\title{
Study on Post-Transformation Assessment and Green Renewal of Binjiang in Shanghai
}

\author{
Pan Hongyan ${ }^{\mathbf{1}^{*}}$, Zhang Gaijing ${ }^{1}$ \\ ${ }^{1}$ Shanghai Research Institute of Building Science Co., Ltd.
}

\begin{abstract}
This paper takes the Binjiang industrial zone of Shanghai as the research object, based on the transformation and development of Binjiang in Shanghai and the renewal of existing urban industrial buildings in recent years, takes green building as the focus to vigorously promote the sustainable and energysaving development of the region. With the goal of improving the vitality and quality of the city, it explores a progressive and sustainable organic regeneration model for the riverfront industrial zone. Through the research and analysis of "green growth and ecological renewal", it establishes a comprehensive posttransformation impact assessment system for the Binjiang industrial belt with three dimensions of transformation connotation: assessment object, functional positioning and transformation direction.Binjiang in Yangpu District and Binjiang in Xuhui District are used as cases for assessment and analysis, and four aspects of industrial function upgrading, building green growth, environmental quality improvement, and industrial culture inheritance are proposed to develop green renewal development strategies for the transformation and development of Binjiang, which provide technical support for the transformation of the future urban Binjiang industrial belt.
\end{abstract}

\section{Introduction}

The master plan of "Shanghai 2035" proposed to make Shanghai a desirable city of innovation, humanities and ecology, with the goal of improving the vitality and quality of the city. It actively explores a progressive and sustainable organic renewal model, preserves and inherits urban culture, promotes the use of space to intensive and compact, functionally complex and low-carbon efficient. Binjiang in Shanghai has become an important area to carry the core functions of the global city in the "Shanghai 2035" urban master plan. Similar to the deindustrialization process of urban waterfronts worldwide ${ }^{[1]}$, Binjiang in Shanghai has undergone a development of functional metabolism and green renewal, with the former industrial functions being re-substituted by new functions such as entertainment, commerce and offices, the quality of the ecological environment being upgraded, and the waterfront public open space shared by citizens being full of urban vitality. In such a context, this paper establishes a comprehensive impact assessment system for the post-transformation of the riverfront industrial zone through relevant studies, standards and theories and other literature studies ${ }^{[2]}{ }^{[3]}[4]$, and proposes a green renewal strategy for the transformation and development of the riverfront industrial zone to provide an important supporting force for the transformation of the city's riverfront industrial belt.

\section{The post-transformation assessment system}

Binjiang in Shanghai experienced the push of the city expo, urban renewal, and in ecology, culture, industry import, functional positioning has been greatly enhanced as well as the promotion and support of the policy at the government level. The impact of policy, economy, and environment etc. needs to be assessed from the heritage protection, green transformation, ecological environment improvement, and the existing industrial zone of functional form enhancement development to carry out the comprehensive assessment of the impact after the transformation.

\subsection{Assessment model}

Taking the Binjiang industrial belt as the object to establish a post-transformation comprehensive impact model from three dimensions of assessment object, functional positioning and transformation ${ }^{[5]}$, we create a first-level objective of post-transformation comprehensive impact assessment covering planning and development, operation and management, cultural continuation, ecological regeneration and vitality perception around macro conditions, protection and utilization, ecological quality, personnel feeling and operation mode. 


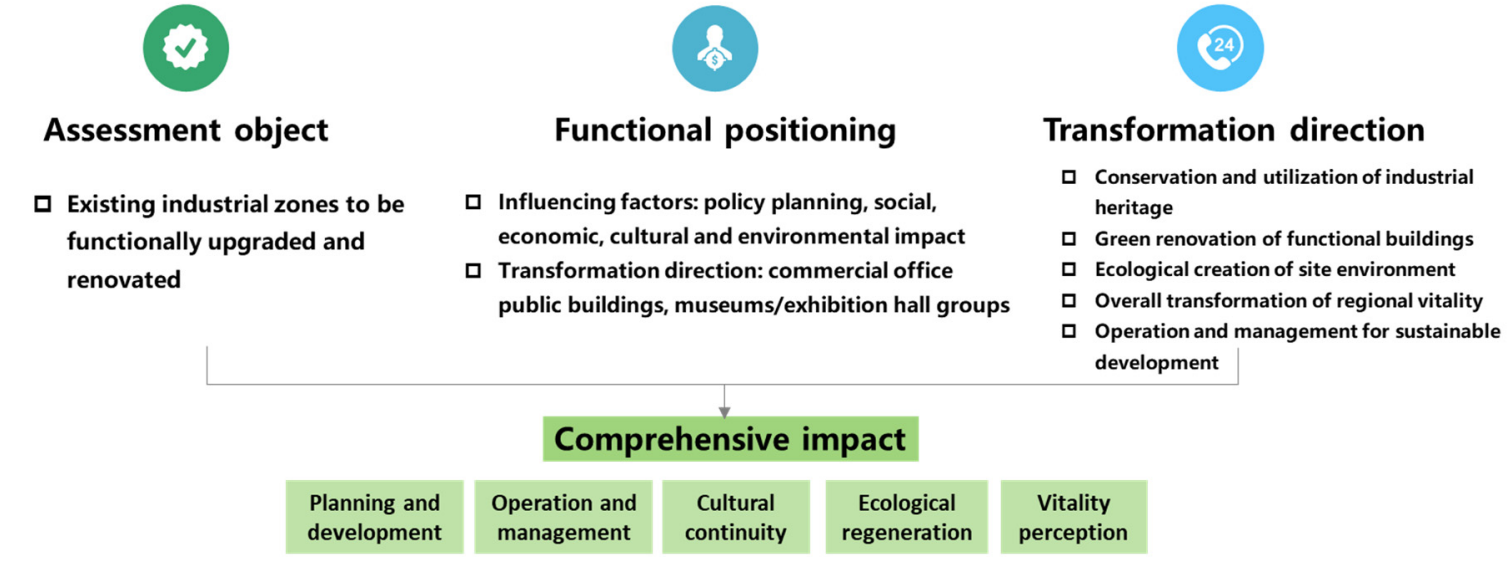

Figure 1. Comprehensive Impact Assessment Model

\subsection{Post-assement Objectives}

Based on the comprehensive impact model, a postassessment target system is established, in which the planning and development impact assessment targets focus on comprehensive economic strength, functional positioning matching degree, and policy implementation degree. The operation management influence focuses on the operation management mode, green economic benefits, and the creation of innovative demonstration projects. Cultural continuity impact focuses on historical longevity, cultural memory, iconic initiatives, increase in cultural and creative enterprises, and satisfaction with cultural full atmosphere. The impact of site regeneration focuses on the natural environment of the site, sustainable use of resources, green building ratio, plant community creation, and greening coverage ratio. Vitality perception influence focuses on public open space vitality, traffic convenience, shared intelligent facility experience, cultural activity richness, and service facility diversity.

Based on literature research, combing relevant standards and norms, questionnaire surveys and statistical analysis of big data, the post-assessment target system indicators are assigned in Table 1 Table 5.

Table 1. Goals of planned development impact assessment

\begin{tabular}{|c|c|c|}
\hline Assessment factors & $\begin{array}{l}\text { Assessment } \\
\text { score }\end{array}$ & Assessment Objectives \\
\hline \multirow{2}{*}{ Comprehensive economic strength } & 0 points & $\begin{array}{l}\text { The GDP growth of the district where the project is } \\
\text { located doesn't not meet the target value. }\end{array}$ \\
\hline & 2 points & $\begin{array}{l}\text { The GDP growth in the district where the project is located meets the } \\
\text { target value. }\end{array}$ \\
\hline \multirow{2}{*}{$\begin{array}{l}\text { Matching rate of Functional } \\
\text { positioning }\end{array}$} & 0 points & $\begin{array}{l}\text { The functional positioning of the project meets the requirements of the } \\
\text { preliminary planning. }\end{array}$ \\
\hline & 1 point & $\begin{array}{l}\text { The functional positioning of the project does not meet the requirements } \\
\text { of the preliminary planning. }\end{array}$ \\
\hline \multirow{3}{*}{ Degree of policy implementation } & 1 point & $\begin{array}{l}\text { At least } 1 \text { incentive policy has been implemented in the project for the } \\
\text { functional upgrading and transformation of existing urban industrial } \\
\text { areas. }\end{array}$ \\
\hline & 2 points & $\begin{array}{l}\text { At least } 2 \text { incentive policies have been implemented in the project for } \\
\text { the functional upgrading and transformation of existing urban industrial } \\
\text { areas. }\end{array}$ \\
\hline & 4 points & $\begin{array}{l}\text { At least } 3 \text { incentive policies have been implemented in the project for } \\
\text { the functional upgrading and transformation of existing urban industrial } \\
\text { areas. }\end{array}$ \\
\hline
\end{tabular}

Table 2.Goals of O\&M impact assessment

\begin{tabular}{|c|c|l|}
\hline $\begin{array}{c}\text { Assessment } \\
\text { factors }\end{array}$ & $\begin{array}{c}\text { Assessment } \\
\text { score }\end{array}$ & \multicolumn{1}{|c|}{ Assessment criteria } \\
\hline \multirow{2}{*}{$\begin{array}{c}\text { Operations } \\
\text { Management } \\
\text { Model }\end{array}$} & 2 points & $\begin{array}{l}\text { The management body has obtained the relevant management system certification, with } \\
\text { ISO14001 environmental management system certification, and ISO9001 quality } \\
\text { management system certification }\end{array}$ \\
\cline { 2 - 3 } & 4 points & $\begin{array}{l}\text { Have a complete management system, including management departments, division of } \\
\text { responsibilities, management content, management processes, etc. }\end{array}$ \\
\cline { 2 - 3 } & 6 points & $\begin{array}{l}\text { The management model includes energy and water saving performance assessment } \\
\text { incentives in the work assessment system }\end{array}$ \\
\hline & 0 points & No significant improvement in green economics compared to the previous year \\
\hline
\end{tabular}




\begin{tabular}{|c|c|l|}
\hline $\begin{array}{c}\text { Green Economic } \\
\text { Benefits }\end{array}$ & 2 points & Significant improvement in green economy compared to the previous year \\
\hline $\begin{array}{c}\text { Creating } \\
\text { innovative } \\
\text { demonstration } \\
\text { projects }\end{array}$ & 0 points & No honours for demonstration projects \\
\cline { 2 - 3 } & 1 point & Awarded the honorary title of Model Project \\
\hline
\end{tabular}

Table 3. Goals of cultural continuity impact assessment

\begin{tabular}{|c|c|c|}
\hline Assessment factors & $\begin{array}{l}\text { Assessment } \\
\text { score }\end{array}$ & Assessment criteria \\
\hline \multirow{3}{*}{ Historicity } & 1 point & Existing industrial areas newly built over 50 years ago \\
\hline & 2 points & Existing industrial areas newly built over 70 years ago \\
\hline & 4 points & Existing industrial areas built over 100 years ago \\
\hline \multirow[t]{2}{*}{ Cultural memorability } & 0 points & $\begin{array}{l}\text { Not retaining elements of the original character of the industrial area as a cultural } \\
\text { landscape }\end{array}$ \\
\hline & 2 points & The original character of the industrial area has been preserved as a cultural landscape \\
\hline \multirow{3}{*}{ Iconic initiatives } & 2 points & A landmark innovation in the renewal process \\
\hline & 4 points & Two landmark innovations in the renewal process \\
\hline & 6 points & Three landmark innovations in the renewal process \\
\hline \multirow{5}{*}{$\begin{array}{l}\text { Increase in cultural and } \\
\text { creative enterprises }\end{array}$} & 3 points & $0<\mathrm{Z} \leq 3 \%$ \\
\hline & 5 points & $3 \%<\mathrm{Z} \leq 7 \%$ \\
\hline & 8 points & $7<\mathrm{Z} \leq 10 \%$ \\
\hline & 10 points & $10<\mathrm{Z} \leq 15 \%$ \\
\hline & 15 points & $\begin{array}{l}\mathrm{Z}>15 \% \\
\text { "Z" indicates the increase in the number of cultural and creative enterprises over the } \\
\text { previous year }\end{array}$ \\
\hline \multirow{3}{*}{$\begin{array}{l}\text { Cultural atmosphere } \\
\text { satisfaction }\end{array}$} & 3 points & Satisfaction survey pass rate $\geq 60 \%$ \\
\hline & 6 points & Satisfaction survey pass rate $\geq 75 \%$ \\
\hline & 9 points & Satisfaction survey pass rate $\geq 90 \%$ \\
\hline
\end{tabular}

Table 4. Goals of ecological regeneration impact assessment

\begin{tabular}{|c|c|c|}
\hline Assessment factors & $\begin{array}{l}\text { Assessment } \\
\text { score }\end{array}$ & Assessment criteria \\
\hline \multirow{3}{*}{$\begin{array}{l}\text { The natural } \\
\text { environment of the site }\end{array}$} & 1 point & One or more of the site's wind, thermal and runoff simulations meet the standards. \\
\hline & 2 points & Two or more of the site's wind, thermal and runoff simulations meet the standards. \\
\hline & 3 points & Three or more of the site's wind, thermal and runoff simulations meet the standards. \\
\hline \multirow[t]{2}{*}{$\begin{array}{l}\text { Sustainable use of } \\
\text { resources }\end{array}$} & 1 point & $\begin{array}{l}\text { Three dimensions of sustainable resource use: } \geq 1 \% \text { renewable energy use, } \geq 1 \% \text { non- } \\
\text { conventional water use, } 50 \% \text { recycling of } C \& D \text { materials. } \\
\text { Achievement of } 1 \text { or more of the above requirements. }\end{array}$ \\
\hline & 2 points & Achievement of 2 or more of the above three requirements. \\
\hline \multirow{2}{*}{$\begin{array}{l}\text { Percentage of buildings } \\
\text { going green }\end{array}$} & 1 point & $\begin{array}{l}\text { The proportion of green buildings in new buildings } \geq 50 \% \text {, the proportion of energy } \\
\text { consumption per unit of floor area reduced by } \geq 10 \% \text { after green renovation of existing } \\
\text { buildings. }\end{array}$ \\
\hline & 2 points & $\begin{array}{l}\text { The proportion of green buildings in new buildings } \geq 70 \% \text {, the proportion of energy } \\
\text { consumption per unit of floor area reduced by } \geq 15 \% \text { after green renovation of existing } \\
\text { buildings. }\end{array}$ \\
\hline \multirow{3}{*}{$\begin{array}{l}\text { Plant community } \\
\text { creation }\end{array}$} & 2 points & $0.2<\mathrm{N} \leq 0.4$ \\
\hline & 4 points & $0.4<\mathrm{N} \leq 0.6$ \\
\hline & 7 points & $\begin{array}{l}\mathrm{N}>0.6 \\
\text { "N" indicates native woody plant index. }\end{array}$ \\
\hline \multirow{3}{*}{ Greenery coverage } & 1 point & $30 \% \leq$ green space ratio $<35 \%$ \\
\hline & 3 points & $35 \% \leq$ green space ratio $<50 \%$ \\
\hline & 5 points & Green space ratio $\geq 50 \%$ \\
\hline
\end{tabular}

Table 5. Goals of Vitality Perception Impact Assessment

\begin{tabular}{|c|c|l|}
\hline Assessment factors & $\begin{array}{c}\text { Assessment } \\
\text { score }\end{array}$ & \multicolumn{1}{|c|}{ Assessment criteria } \\
\hline $\begin{array}{c}\text { Public open space } \\
\text { vibrancy }\end{array}$ & 1 point & 300 coverage of public open space vitality nodes of no less than $80 \%$. \\
\cline { 2 - 3 } & 3 points & 300 coverage of public open space vitality nodes of at least $90 \%$. \\
\hline \multirow{3}{*}{ Accessibility } & 1 point & No less than $70 \%$ coverage of 500 service radius of bus stops. \\
\cline { 2 - 3 } & 2 points & No less than $80 \%$ coverage of 500 service radius of bus stops. \\
\cline { 2 - 3 } & 4 points & No less than $90 \%$ coverage of 500 service radius of bus stops. \\
\hline $\begin{array}{c}\text { Shared intelligent } \\
\text { facility experience }\end{array}$ & 1 mark & At least three human-accessible public facilities with intelligent experience features. \\
\cline { 2 - 3 } & 2 points & At least five human-accessible public facilities with intelligent experience features. \\
\hline
\end{tabular}




\begin{tabular}{|c|c|c|}
\hline \multirow{4}{*}{ Recreational activities } & 3 points & $20 \% \leq \mathrm{X}<30 \%$, and $30 \% \leq \mathrm{Y}<50 \%$ \\
\hline & 6 points & $30 \% \leq \mathrm{X}<40 \%$, and $50 \% \leq \mathrm{Y}<60 \%$ \\
\hline & 9 points & $40 \% \leq \mathrm{X}<50 \%$, and $60 \% \leq \mathrm{Y}<70 \%$ \\
\hline & 12 points & $\begin{array}{l}\mathrm{X} \geq 50 \% \text {,and } \mathrm{Y} \geq 80 \% \\
\text { "X" indicates the frequency of recreational activities, and "Y" indicates the type of } \\
\text { recreational activity. }\end{array}$ \\
\hline \multirow{3}{*}{$\begin{array}{l}\text { Diversity of service } \\
\text { facilities }\end{array}$} & 2 points & At least 5 types of service facilities and at least $90 \%$ compliance with features. \\
\hline & 5 points & At least 7 types of service facilities and at least $80 \%$ compliance with features. \\
\hline & 8 points & $\begin{array}{l}\text { At least } 9 \text { types of service facilities and at least } 70 \% \text { compliance with the } \\
\text { characteristics. }\end{array}$ \\
\hline
\end{tabular}

\subsection{Analysis of Binjiang Assessment}

Around the vision of Shanghai to build "an excellent global city", according to the unified plan of the municipal government, according to the requirements of "hundred years plan, century fine", Binjiang in Yangpu District and Binjiang in Xuhui District and other "riverfront industrial zone "adhere to the" ecology first, function first "based on" reproducing the style and reshaping the function". They focus on the riverfront public space through the project, accelerate the planning, pay attention to the construction, connect the breakpoint, focus on reflecting the characteristics, and inherit industrial civilization. Efforts are made to build it into a public space and living shoreline that serves the public for fitness and leisure, sightseeing and tourism. Combining the development and characteristics of the two cases [6] [7] [8] [9], the comprehensive impact assessment analysis after the transformation is carried out. The assessment is as follows.

\begin{tabular}{|c|c|c|c|}
\hline \multicolumn{2}{|r|}{ Case assessment } & \multirow{2}{*}{$\begin{array}{c}\begin{array}{c}\text { Binjiang in } \\
\text { Yangpu District }\end{array} \\
\text { Assessment }\end{array}$} & \multirow{2}{*}{\begin{tabular}{|c|}
$\begin{array}{c}\text { Binjiang in Xuhui } \\
\text { District }\end{array}$ \\
Assessment \\
\end{tabular}} \\
\hline Primary goal & Secondary goals & & \\
\hline \multirow{3}{*}{$\begin{array}{l}\text { Planning and } \\
\text { development }\end{array}$} & Comprehensive economic strength & & \\
\hline & Matching rate of functional positioning & & \\
\hline & Degree of policy implementation & & \\
\hline \multirow{3}{*}{$\begin{array}{l}\text { Operation and } \\
\text { management }\end{array}$} & Operation and management model & & \\
\hline & Green economic benefits & & \\
\hline & Creation of innovative demonstration projects & & \\
\hline \multirow{5}{*}{ Cultural continuity } & Historical longevity & & \\
\hline & Cultural memorability & & \\
\hline & Iconic initiatives & & \\
\hline & Increase ofcultural and creative enterprise & & \\
\hline & Cultural atmosphere satisfaction & & \\
\hline \multirow{5}{*}{$\begin{array}{l}\text { Ecological } \\
\text { regeneration }\end{array}$} & Natural environment of the site & & \\
\hline & Sustainable use of resources & & \\
\hline & Ratio ofgreen building & & \\
\hline & Plant community creation & & \\
\hline & Greening coverage rate & & \\
\hline \multirow{5}{*}{ Vitality perception } & Vitality of public open space & & \\
\hline & Convenience of transportation & & \\
\hline & Experience of shared intelligent facilities & & \\
\hline & Richness of cultural and recreational activities & & \\
\hline & Diversity of service facilities & & \\
\hline
\end{tabular}

Figure 2. After the transformation of the growth of the riverside evaluation schematic

Its planning and development and operation management for supporting the transformation of the riverfront industrial zone is an important foundation, while the industrial history and culture, architectural style, and cultural memory, etc. are also important factors for the continuation of the Binjiang industrial history and culture, and activation of post-transformation development. As a measure of post-transformation sustainable aspects, good ecological environment quality to enhance the green quality of the riverfront space, including for the use of resources and energy, building green regeneration, the creation of landscape plant communities, etc., construction and operation of the growing riverfront is gradually open to positive development, and evaluation of the riverfront live strength of some factors are becoming an important basis for judging the attractiveness of the riverfront, such as important nodes of public space live strength, shared Intelligent service facilities in Binjiang, cultural and creative activities, etc. Binjiang in Yangpu District has achieved a good demonstration in public space and architectural art level, and the West Coast has also had a positive impact in terms of intelligence and cultural creativity. 


\section{Strategy for green renewal in Binjiang}

According to the transformation and development of Binjiang in Shanghai and the model of post-assessment comprehensive influence, from the upgrading of industrial functions in the early stage, to the green renewal of current buildings, from the improvement of environmental quality, to the inheritance of industrial culture, the transformation and upgrading of the industrial zone of Binjiang are carried out by formulating a sustainable development strategy of green renewal.

\subsection{Upgrading of industrial functions}

Create a waterfront area that is suitable for business, living, fun and tourism, build an ecological industrial development system in the riverside area, and create a cultural cluster with regional characteristics along the river. Binjiang in Yangpu District is gradually developed into an innovative development belt with international influence. From "industrial rust belt" to "industrial show belt", it has transformed into a "people's city for the people" model place. Binjiang in Xuhui District is aligned with the Left Bank of Paris and the South Bank of London, and has opened a chapter of urban renewal from a production-oriented shoreline to a living-oriented shoreline, and has updated its positioning for art, sports, business, culture and technology functions, implementing the "Double A" plan for the West Bank, namely "ART" art and "AI" artificial intelligence, aiming to create a diversified industrial and cultural ecology.

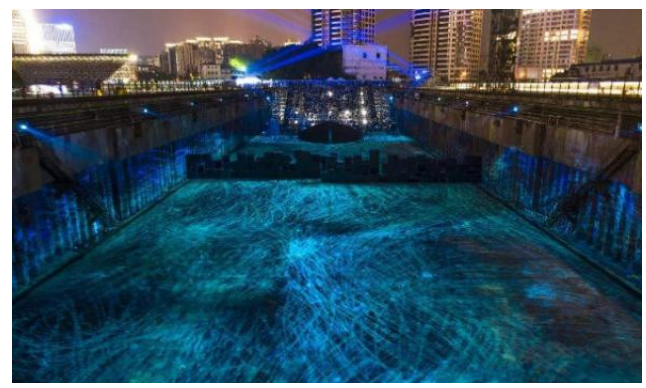

Figure3. Artificial Intelligence Center in Binjiang, Xuhui District, South Dock Public Space in Binjiang, Yanpu District

\subsection{Green growth of buildings}

The transformation of the waterfront industrial zone brings new growth space for urban construction, and the new buildings create green and healthy class buildings, and provide green indoor space for the people living and working through the construction of high standard and high quality green building groups, while encouraging green transformation for buildings with certain historical significance that can be reused to achieve the goal of saving resources and protecting the environment for the whole life of the buildings. Take the former building of the tobacco company as an example, although the age limit of the construction and the craftsmanship don't have a conservation value, in the context of enhancing the overall landscape appearance and playing the demand of the maximum utilization of the building, the building is retained for green renewal, making it an urban riverfront complex integrating municipal infrastructure, public green space and public supporting services. It utilizes the retreat of the planned green space on the north side of the current Chinese tobacco warehouse to extend the city side, forming a gentle slope to access the city, mulching and planting on the slope to build a park, and arranging parking and other basic services under the slope so that people can stroll from the city to the riverbank unconsciously ${ }^{[10]}$.
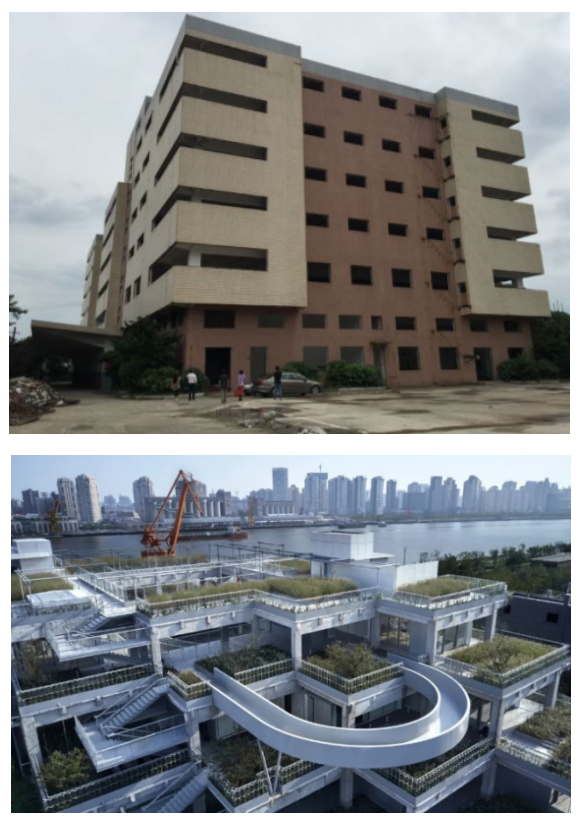

Figure4. Cigarettes Factory and Green hill after transformation

\subsection{Improvement of environmental quality}

By improving soil quality, we can create a reasonable plant community, improve the quantity and quality of plants, better play its value in the ecosystem, maintain the balance of the ecosystem, and adopt an ecological restoration strategy. At the same time, the water-friendly platform and public space have changed the old environment along the river, improved the waterfront ecological environment, created a riverfront landscape and water-friendly public space, improved the overall image of the city, and realized the "returning the river to the people", and Greenland Plaza has created a sponge park landscape by practicing development with low impact.

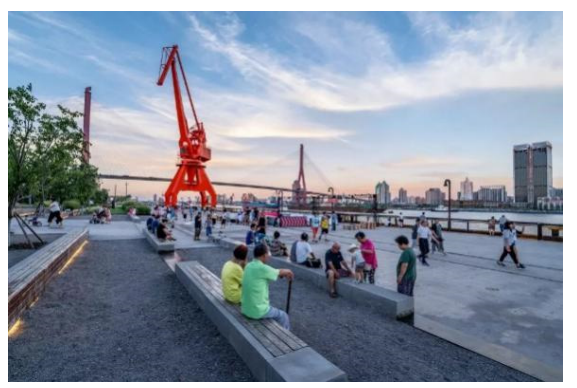

Figure5. Xuhui Rrverid Public Open Space 


\subsection{Heritage of industrial culture}

The industrial zone along the riverfront carries many cultural memories. The protection and inheritance of these historical elements with industrial cultural values is not only an important carrier for the protection of public awareness of history and culture, but also a cultural memory for the protection of public life from generation to generation. Through the protection of historical culture, historical style buildings and industrial relics along the riverfront, we inherit the spirit of sea culture and urban culture, and inject cultural connotation into the development of the Binjiang. Taking the Longhua Airport in Binjiang, Xuhui District as an example, the renovated Longhua Airport runway shows the imprint of aviation history, adopts the design concept of urban trajectory, organizes streets and parks into a unified runway system with diversified linear spaces, intersperses water systems and greenland, and sets up rain gardens in combination with the sponge city concept, transforming the former Longhua Airport runway into a runway for cars, bicycles, people and rivers, forming a beautiful urban public space integrating history and landscape.

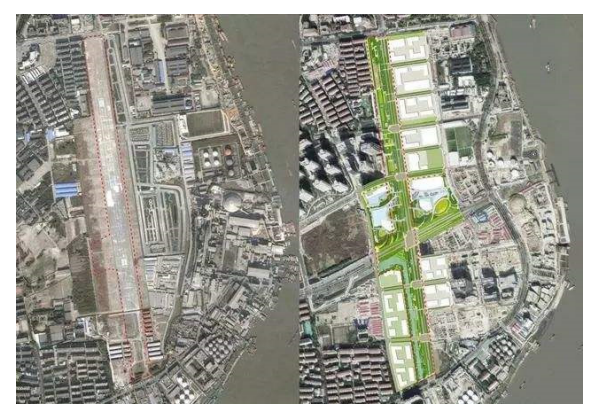

Figure6. Xuhui Runway Park

\section{Conclusion}

Based on the transformation and development of Binjiang in Shanghai in recent years, this paper explores a progressive and sustainable organic regeneration model for the riverside industrial zone with the goal of improving the vitality and quality of the city. Through the research and analysis of "green growth and ecological renewal", we have established a comprehensive impact assessment system for the transformation of the riverfront industrial zone with three dimensions of transformation connotation, including assessment object, functional positioning and transformation. Taking Binjiang in Yangpu District and Binjiang in Xuhui District as the cases for assessment and analysis, we have proposed a green renewal development strategy for the transformation and upgrading of the Binjiang in four aspects: industrial function upgrading, green building growth, environmental quality improvement and industrial culture inheritance, and provided technical support for the transformation of the Binjiang industrial belt in the future.

\section{Acknowledgments}

This paper is supported by the National Key Research and Development Program of China (Project No. 2018YFC0704900).

\section{References}

1. Ding Fan, Wu Jiang. A study of waterfront revitalization mechanisms in post-industrial cities in the context of globalization: the case of the west bank of the Huangpu River in Shanghai[J]. Modern Urban Research, 2018(1):25-34.

2. Assessment standard of green ecological urban area GB/T 51255

3. Assessment standard for green industrial buildings GB/T 50878

4. Assessment standard for green renovation of existing buildings GB/T 51141

5. Yue X Y, Pan H Y, Tang P, et al. A study on the post-evaluation system of functional upgrading and transformation for old urban industrial areas[J]. IOP Conference Series: Earth and Environmental Science, 2020, 615(1):012047 (7pp).

6. Yang Dan. Cultural planning of urban waterfront: the practice of "West Coast Cultural Corridor" as an example[J]. Shanghai Urban Planning, 2015, 006(006):111-115.

7. Yang Chunxia, Han Qi, Geng Huizhi. Analysis of the urban vitality of Bartley Park City, New York, and suggestions for the enhancement of the Huangpu River area in Shanghai[J]. Urban Design, 2020, No.027(01):47-58.

8. Huang Yuanyuan, Huang Lei. Vitality of waterfront space in the post-Expo era and the problem of reengineering: the case of Changsha and Shanghai[J]. Chinese and foreign architecture, 2020, No.234(10):20-27.

9. Chen Bing. Why the industrial zone on both sides of the Huang Pu River is turning into a living $\operatorname{room}[\mathrm{J}]$. Xinmin Weekly, 2019, 000(050):P.26-29.

10. Ju Xi, Zhang Ming, Qin Shu. Renewal and renovation of the former tobacco company's machine repair warehouse in Binjiang, Yangpu District, Shanghai [J]. Time Architecture, 2020, 000(001):92-99 